\title{
Using Thermal Manikin Systems for Thermophysiological Comfort Evaluations- A Review
}

\author{
Esra Taştan Özkan* \\ Bitlis Eren University, Turkey
}

*Corresponding author: Esra Taştan Özkan, Bitlis Eren University, Fine Arts Faculty, Textile and Fashion Design Department, Turkey.

Received Date: December 18, 2020

Published Date: February 10, 2021

\begin{abstract}
Thermal manikins are devices used especially for heat and moisture transfer measurements due to their human form shape and their ability to sweat and move. Thermal manikins generally work in uniform form and at constant surface temperatures representing skin temperature near neutral. The main aim of this work was to investigate the types of thermal manikins and their properties and to talk about the works done using thermal manikins from the past to the present. As a result, thermal manikin systems give better results than wear trials, especially in the measurement of sportswear due to the sweating and movement functions of the systems.
\end{abstract}

Keywords: Water vapor resistance; Thermal resistance; Thermal manikins; Standards

\section{Introduction}

The thermal manikin is one of the tools used to evaluate the thermal comfort of the garment and layered clothing systems. Thermal manikins for measuring thermal properties of garments, compared to other methods allow the investigation of multidimensional garments.

Thermal manikins are a widely used device for thermal resistance and evaporation resistance measurements in clothes, as they give precise results as well as repeatability and ease of tests. The first thermal manikins were produced by the US military in the early 1940s. Later, thermal manikins with different body parts, inability to sweat and movement abilities were produced. In terms of functionality, thermal manikins can be divided into three different categories. These are: a) immobile and non-sweating thermal manikins b) thermal manikins that cannot move but can sweat c) thermal manikins that can move and sweat. Examples of these are Coppellius produced in Finland and Walter produced in Hong Kong [1]. Some of the researches about this subject were given below:
Fan J, et al. [2] in this study, the thermal manikins and its internal structure are shown (Figure 1). The manikin is hung from the head of a water pipe, which also supplies water to the manikin's body. The manikin is covered with a layer of water repellent breathable leather and filled with water. In the centre of the body, there is an internal heating system and provides heat to the body, and there is a water circulation system that sends the heat of two pumps and pipes to the head and limbs. The skin is very important because it not only provides sweating but also keeps up to $100 \mathrm{~kg}$ of water in the body. For this, a special fabric used in marine applications was provided from Goretex (Figure 2).

Fan J, et al. [3] made a study that gave information about the working principle of the sweating thermal manikin Walter. In the study, the time-dependent change and measurement of water source and water simulating sweating were provided. The results revealed the impact of movement and fit on thermal and evaporation resistance of the garment.

Kuklane $\mathrm{K}$, et al. [4] investigated different shape and size 
thermal manikins like Lady, Tore and baby manikins. They compared according to 1) tight and loose clothing; (2) serial and parallel calculation models; (3) even and uneven clothing (insulation) distribution; and (4) the effect of wearing clothes. They declared that depending on body shape, the man and female manikins showed different test results (Figure 3).
Elabbassi EB, et al. [5] compared two premature newborn sized manikins according to body heat loss difference. The results showed that heat loss increased with increasing body surface area to body mass ratio. It has also been reported that thermal manikins are more accurate than current mathematical or other measurement techniques for evaluating temperature changes (Figure 4).
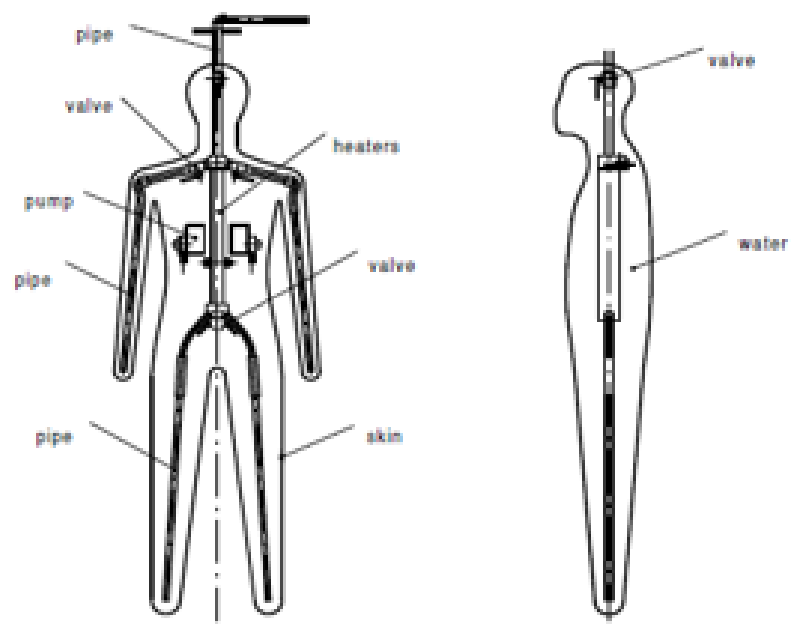

Figure 1: Thermal manikin and its internal structure (Fan and Chen, 2002).

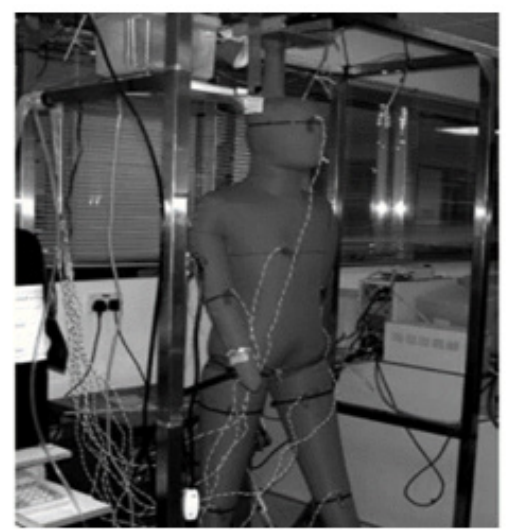

Figure 2: Walter in walking motion ( Fan and Qian, 2004)

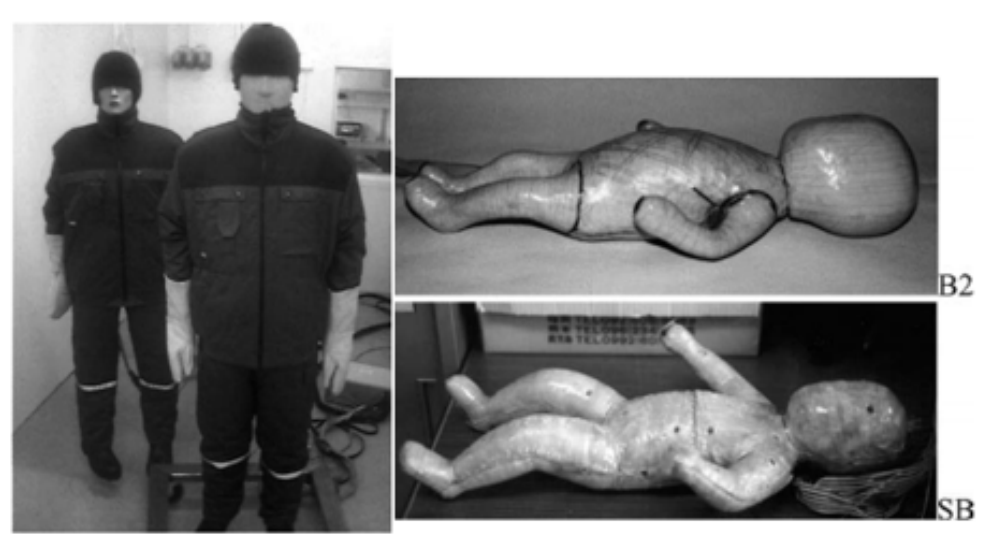

Figure 3: Lady, Tore and Baby thermal manikins (Kuklane et al., 2004). 

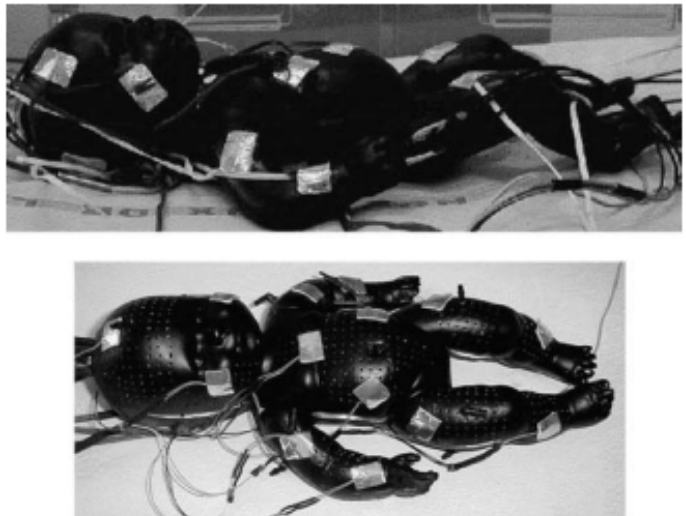

Figure 4: Large and small baby thermal manikins (Elabbassi EB, et al. 2004).

Melikov (2004), studied breathing thermal manikins for inside environment measurements. They stated that breathable thermal manikins can be used to judge the thermal comfort and breathing air quality of the passengers in buildings and vehicle cabins to evaluate the thermal comfort and breathing air quality of passengers in buildings and vehicle cabins [6].

Tamura T [7] in this study, a two-layered, mobile, walking, sweating thermal manikin was developed (Figure 5). It consists of the inner part on the manikin body and an outer covering part consisting of 17 parts which are independently controlled by the heat source. The sweating rate of 180 pores in the skin is controlled by peristaltic pumps. The temperature performance of the manikin is examined using thermography (thermal camera).

Celcar D, et al. [8] a thermal manikin named Coppelius was used in this study. This manikin was developed on the basis of Tore, a Swedish dry manikin, and added sweating mechanism. The sweating manikin consists of 18 individually controlled, electrically heated body parts. Due to the 187 individually controlled sweating channels, continuous sweating is realized. The shape of the manikin allows movement in the shoulders, wrists, hips and knees. Figure 6 shows the test environment and the sweat channels of the thermal manikin.

Wang F [9] compared the multi-segment thermal manikin Newton and the one-segment thermal manikin Walter. They declared that in Walter thermal resistance and water vapour resistance can be calculated at once. On the other hand, in Newton that thermal resistance can be measured with dry test or water vapour resistance can be measured with a wet test (Figure 7).

Wang F, et al. [10] coped with the difficulties of adding temperature sensors to the wet skin surface and to measure the evaporation resistance more precisely, a sensitive leather model was developed on the thermal manikin TORE. In this study, wetting of a dry and warmed Tore thermal manikin with perspiration was simulated using a knitted structure that fits snugly on the body. Depending on the assumed skin temperature, an international skin temperature empirical equation has been developed. Wire temperature sensors utilized in the evaluation of the surface temperatures of the naked manikin (Figure 8).
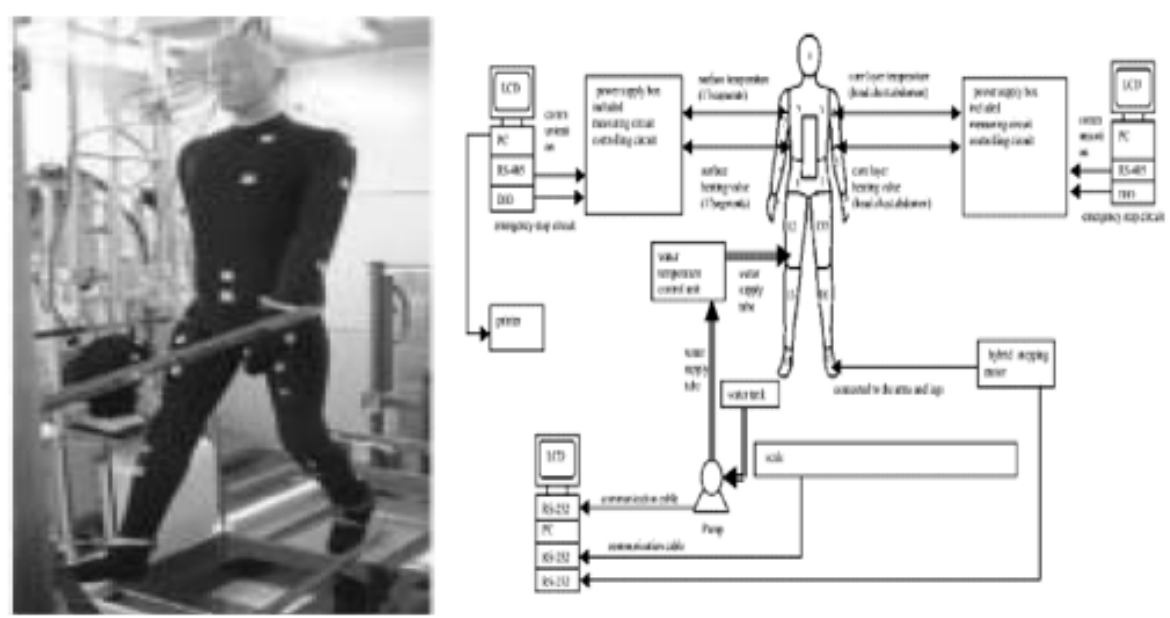

Figure 5: Thermal manikin JUN (Tamura T 2006). 

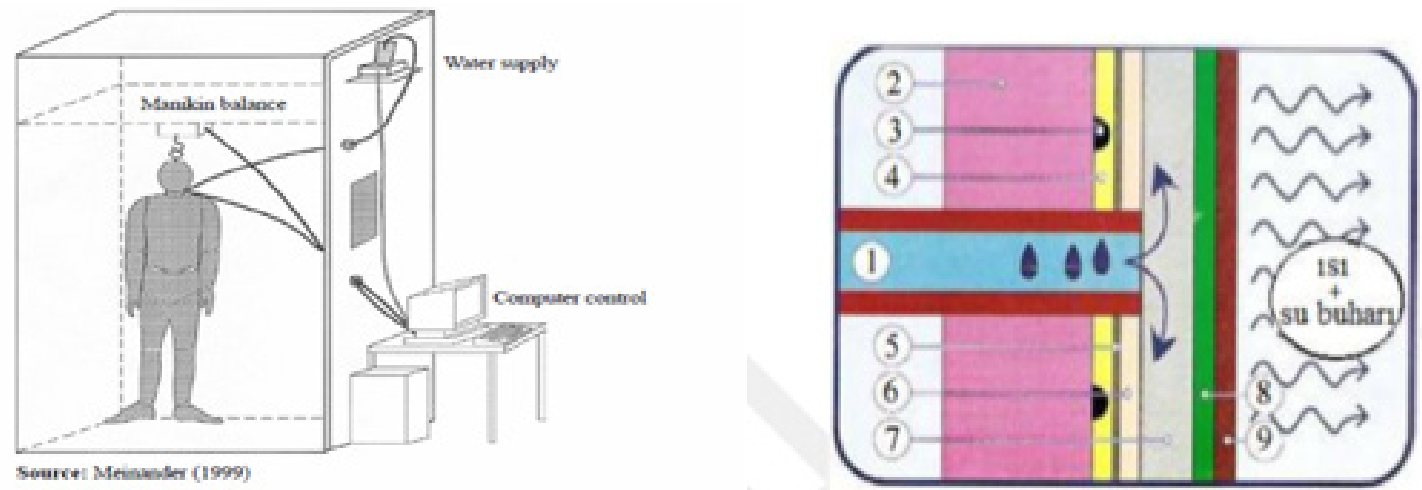

Figure 6: Sections of Coppelius and sectional view of thermal mannequin sweat gland [1].

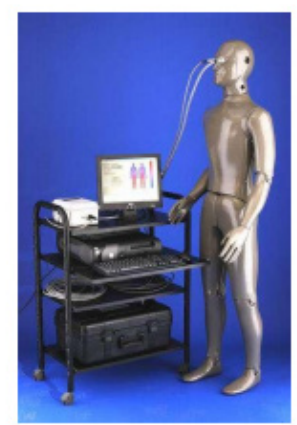

(a)

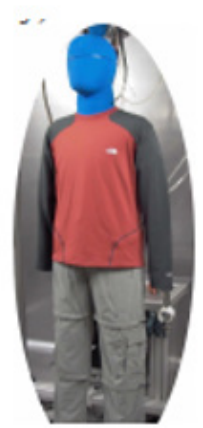

(b)

Figure 7: a) 20 zones thermal manikin Newton, b) One segment thermal manikin Walter (Wang F 2008).

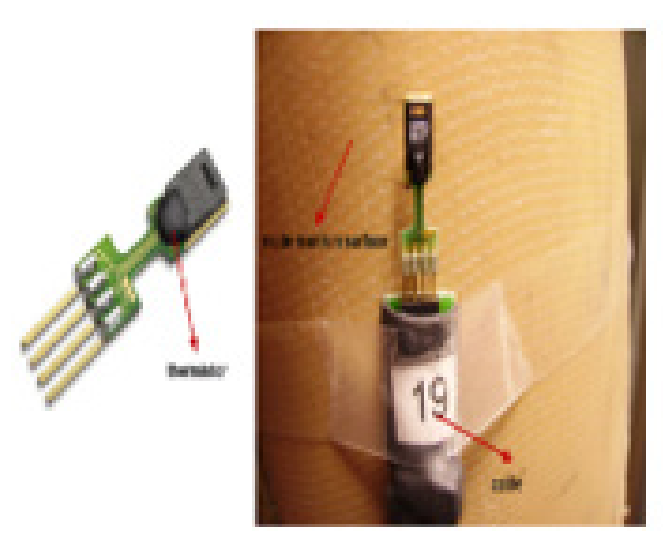

Figure 8: Temperature sensor (Wang F, et al., 2010).
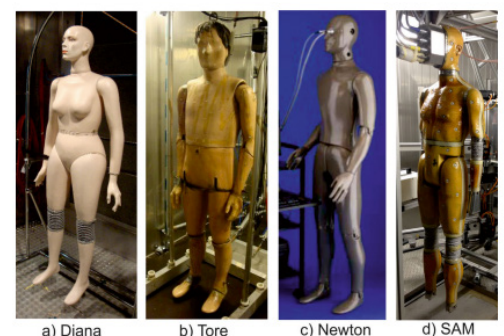

Figure 9: Four Thermal manikins a)Diana, b) Tore, c) Newton, d) SAM ( Al-ajmi FF, et al., 2008). 


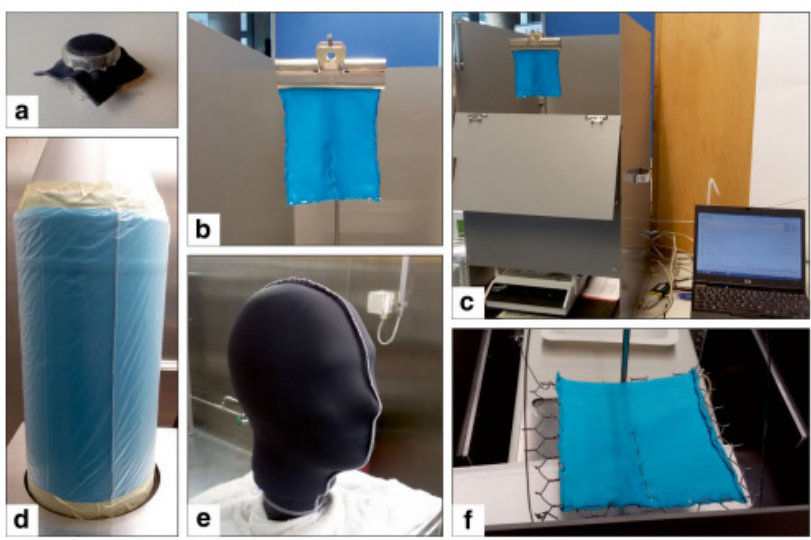

Figure 10: a) sample for contact angle measurement b) MMC measurement c) MMC experimental setup d)thermal resistance measurement e) Skin for head manikin test f) Drying rate measurements [13].

Ho C, et al. [11] studied the effects of plumping and ventilation holes on clothing comfort in terms of thermal resistance and water vapour resistance. Different sizes of T-shirts are obtained with specially added fullness cut and expanded flowing T-shirts. Tests were performed in a controlled environment (temperature, air speed and relative humidity) and a thermal manikin named Walter was used in these tests. The tests were performed under four different conditions: suspended and walking in the windy and windless air. At the end of the tests, it was observed that the added fullness reduced the thermal resistance and water vapour resistance properties of the garment in a stagnant and windy environment.

Psikuta A, et al. [12] investigated the limitations and advantages of currently used thermal manikins due to thermal resistance and heat flux measurements. The compared manikins were named as Tore, Diana, Newton and SAM by their producers. The result showed that all manikins gives quick reaction during passive heating and cooling to simulate alteration of human skin temperature. This study provided information to troubleshoot the performance and potential issues of current and future manikins. Also, some advantages were mentioned like high repeatability, low cost, effectiveness on the contrary to human wear trials.

Koelblen B, et al. [13] compared the different type of fabrics to use a skin in a sweating thermal manikin. For this purpose, three different types of tight fabric produced from cotton, polyester and polyamide were compared with Thermetrics fabric. The standard tests were made (contact angle, MMC measurement, thermal resistance and drying rate) to find which fabric more convenient for skin production. The results showed that the CO, PE, and TH fabrics indicated similarly good results regarding the tests and CO fabric demonstrated the best characteristic for RET measurements.

\section{The Standards Used in Thermal Manikin Measurements}

There are some standards used in thermal resistance measurements with thermal manikins (ISO 9920,2007; ISO 15831,
2004; ASTM F 1291, 2004; EN 342, 2004). Although there is more interest in thermal resistance measurements in dynamic conditions, most of the standards are defined on thermal manikin in the static state. Dynamic heat transfer measurements are a complex issue, as openings in clothing allow air circulation. This phenomenon is called the pumping effect. In addition, body posture, activity level, air speed, sweat accumulation, pressure, thickness, number of layers and the fit of the garment on the body significantly affect the thermal resistance [14].

The standards used for thermal manikin measurements are Nordic standards, European standards, US standards and International standards. Four different types of standards used for measurement in nordic countries. These are INSTA 352 to 355 and the first one introduced around in 1986 for cold protective garments. The second one mentioned production and calculation of thermal manikins. The other ones used for calculation of garment properties.

The first European standard was introduced in 1989 for cold weather protective garments. A German standard was introduced in 2002 for sleeping bags. The US standards were introduced (ASTM-F1291 2005 and ASTM-F1720 1996) to describe a heated thermal manikin and its calculation formulas. The international standards; ISO 7730 used for inside environmental conditions and ISO 7933 used for measurements of garments heat transfer according to thermal and moisture vapour resistance values.

\section{Studies Using Thermal Manikins}

Thermal comfort refers to whether the garment gives the wearer a feeling of heat, cold or humidity and depends on factors such as temperature, humidity and air speed. Some researchers have used thermal manikin systems in their studies:

Nilsson HO [15] produced a new thermal manikin based on data obtained from thermal manikin measurements with a recent comfort assessment method. The results used to produce a recent type of thermal manikin, MANIKIN3, to be helpful in measurements 
of CFD simulations. They proclaimed that there were too many unknown differences in the simulation results.

Ho C, et al. [16] investigated the effects of t-shirt design on garment thermal resistance and moisture vapour resistance properties. It has been observed that the location of the openings and ventilation panels influence the total thermal insulation and vapour resistance. In addition, it was observed that settlement mesh fabric on the armholes of the t-shirt in standing mode did not affect the release of excess body heat.

Fan J, et al. [17] used a thermal manikin 'Walter' and investigated the effects of sportswear on the comfort of athletes during activity. Thermal resistance and moisture vapour resistance properties of five tracksuits were evaluated. The results showed that moisture vapour resistance and amount of moisture affects the thermal comfort sensations.

$\mathrm{Al}$-ajmi FF, et al. [18] investigated thermal resistance and clothing area factors of women and men Arabian gulf clothes. The measurements were made according to ISO 9920 with a thermal manikin. The results added new knowledge to the existing data of clothing insulation for Arabian Gulf clothing (Figure 9)

Wang F [9] presented a new equation to estimate the damp skin surface temperature of sweating thermal manikins. They tried to pass the difficulty of adding temperature sensors to the damp skin surface by extensive skin study on the thermal manikin "Tore".

Ho C, et al. [11] the impact of added fullness and aeration holes on clothing comfort measured in terms of thermal insulation and water vapour resistance. The thermal insulation and water vapour resistance of the T-shirts was calculated in a controlled room using the thermal manikin 'Walter'.

Oliveira AVM, et al. [14] investigated thermal resistance of protective garments in a static condition with the effect of body movements. Thermal manikin 'Maria' was used in the experiments. The thermal resistance of the whole body was calculated using serial, global and parallel methods. The comparative analysis showed that serial method led to highest values.

Ho C, et al. [19] a special t-shirt was produced to research the effect of wider air spaces on the shoulders on heat and moisture transfer properties. To investigate the effect of this t-shirt, a series of tests were conducted in a controlled room using a movable thermal manikin in windy and windless conditions (Figure 10).

Lu Y, et al. [20] searched the impact of body movement and wind on thermal insulation of a type of cloth with a moveable thermal manikin. A new formula was developed according to an equation of local insulation, air velocity, and walking speed. The outcomes indicated that the wind effect interacted with the walking effect and thermal resistance differed significantly between different body parts.

Suganthi T, et al. [21] examined the thermal comfort features of two-layer knitted structures made of polyester and modal/ bamboo yarns. It was noticed that the moisture absorbency of the two-layer knitted fabric increased with the rise of the tightness and loop density. The water vapour permeability of the two-layer fabric has increased with the decline in thickness and the existence of opening in the fabric.

Psikuta A, et al. [22] examined the effects of manikin-based technologies on energy productivity and human response, and their adaptability in the area of environmental engineering, automobile industry and clothing searches. They concluded that this work promotes the exchange of information across disciplines.

Tama D, et al. [23] investigated thermal resistance properties of rowing t-shirts with a thermal manikin. The results showed that thermal insulation of rowing shirts change according to the water repellent finishing treatment. Also, they declared that to investigate the behaviour of climatic change on the thermal resistance of rowing t-shirts, the thermal manikin tests must be conducted in different air temperature and humidity conditions.

$\mathrm{Xu} \mathrm{X}$, et al. [24] a sweating thermal manikin was used to calculate the thermal (Rcl) and evaporation resistance (Recl) and they investigated the effects of fabric structure on the thermal and evaporation the resistance of chemical protective garments. The results showed that measurements of the sweating hot plate and thermal manikin provide a new look for understanding the relation between fabric and clothing.

Lei Z [25] examined the properties, application areas, measurement principles and research situation of some thermal manikins. They stated that thermal manikins can be divided into more body parts. They also stated that smart thermal manikins will emerge in the future and can be operated with a laptop or mobile phone.

Tama D, et al. [26] studied the thermal features of the classic fabric of the Rize city (Feretico). The thermal manikin tests were made at $23{ }^{\circ} \mathrm{C} \pm 1$ temperature and $75 \pm 5 \%$ relative humidity environment like Rize city. The results showed that the drapability and air permeability of hemp fibre was very good and the total garment resistance of the t-shirt made of feretiko fabric was calculated as $0.032 \mathrm{~m}^{2} \mathrm{~K} / \mathrm{W}$ with a thermal manikin.

Guan M, et al. [27] investigated the garment size effect on evaporative cooling and optimization properties of protective clothes with sweating and walking thermal manikin. The results indicated that the impact of garment size on global and local evaporative cooling based on the walking speed. They also recommended a new formula for calculation of global and local evaporative cooling with an effect of garment size, walking speed, and sweat rate.

Rogale D, et al. [28] investigated thermal resistance properties of multi-layer protective jacket with a thermal manikin. The protective jacket composed of five different layers. The results 
showed that increasing the weight of thermal insulation textile materials resulted in an increase in the thermal resistance characteristic of the garment. Also, three new parameters were introduced for assessing thermal properties of garments.

\section{Conclusion}

The type of thermal manikins, working principles and thermal manikin used studies were mentioned in this study. It was concluded that recent developments in thermal manikins enable to better simulate heat and moisture transfer from the human body. Because today's thermal manikins allow the measurement of heat and moisture transfer during activity by simulating the movement of sweating and walking. Thermal manikins are used especially in the measurement of sportswear because they eliminate the disadvantages of wear trials, such as the human factor, the body surface areas of the subjects and long time. On the other hand, the disadvantages of thermal manikins are that the tests are very expensive.

\section{Acknowledgement}

None.

\section{Conflict of Interest}

Author declare no conflict of interest.

\section{References}

1. Meinander H (1999) Extraction of data from sweating manikin tests Proceedings of the Third International Meeting on Thermal Manikin Testing, 3IMM at the National Institute for Working Life.

2. Fan J, Chen Y (2002) Measurement of clothing thermal insulation and moisture vapor resistance using a novel perspiring fabric thermal manikin. J Meas Sci Technol 13(7): 1115-1123.

3. Fan J, Qian X (2004) New functions and applications of Walter, the sweating fabric manikin. Eur J Appl Physiol 92(6): 641-644.

4. Kuklane K, Sandsund M, Reinertsen RE, Tochihara Y, Fukazawa T, et al (2004) Comparison of thermal manikins of different body shapes and size. European Journal of Applied Physiology 92: 683-688.

5. Elabbassi EB, Belghazi K, Delanaud S, Libert J (2004) Dry heat loss in incubator: comparison of two prematüre newborn sized manikins. Eur J Appl Physiol 92(6): 679-682.

6. Melikov A (2004) Breathing thermal manikins for indoor environment assessment: important characteristics and requirements. Eur J Appl Physiol 92(6): 710-713.

7. Tamura $\mathrm{T}$ (2006) Development of a two-layer movable sweating thermal manikin. Industrial Health 44(3): 441-444.

8. Celcar D, Meinander H, Gersak J (2008) Heat and moisture transmission properties of clothing systems evaluated by using a sweating thermal manikin under different environmental conditions. International Journal of Clothing Science and Technology 20(4): 240- 252.

9. Wang F (2008) A comparative introduction on sweating thermal manikins Newton and Walter. $7^{\text {th }}$ International Thermal Manikin and Modelling Meeting, University of Coimbra.

10. Wang F, Kuklane K, Gao C, Holmer I ( 2010) Development and validity of a universal empirical equation to predict skin surface temperature on thermal manikins. Journal of Thermal Biology 35(4): 197-203.
11. Ho C, Fan J, Newton E, Au R (2011) The effect of added fullness and ventilation holes in T-shirt design on thermal comfort. Ergonomics 54(4): 403-410

12. Psikuta A, Kuklane K, Bogdan A, Havenith G, Annaheim S, et al. (2016) Opportunities and constraints of presently used thermal manikins for thermo-physiological simulation of the human body. Int J Biometeorol 60: 435-446.

13. Koelblen B, Psikuta A, Bogdan A, Annaheim S, Rossi RM (2017) Comparison of fabric skins for the simulation of sweating on thermal manikins. Int J Biometeorol 61: 1519-1529.

14. Oliveira AVM, Gaspar AR, Quintela DA (2011) Dynamic clothing insulation: Measurements with a thermal manikin operating under the thermal comfort regulation mode. Applied Ergonomics 42(6): 890-899.

15. Nilsson HO (2007) Thermal comfort evaluation with virtual manikin methods, Building and Environment 42(12): 4000-4005.

16. Ho C, Fan J, Newton E, Au R (2008) Effects of athletic T-shirt designs on thermal comfort. Fibers and Polymers 9(4): 503-508.

17. Fan J, Tsang HW (2008) Effect of clothing thermal properties on the thermal comfort sensation during active sports. Textile Research Journal $78(2): 111-118$.

18. Al-ajmia FF, Loveday DL, Bedwell KH, Havenith G (2008) Thermal insulation and clothing area factors of typical Arabian Gulf clothing ensembles for males and females: Measurements using thermal manikins. Applied Ergonomics 39(3): 407-414.

19. Ho C, Fan J, Newton E, Au R (2015) T-Shirt with Propping Effect for Natural Ventilation: Design Development and Evaluation of its Functionality by Thermal Manikin in Standing and Walking Motions. Textile Science \& Engineering 5(5): 1-7.

20. Lu Y, Wang F, Wan X, Song G, Zhang C, et al. (2015) Clothing resultant thermal insulation determined on a movable thermal manikin. Part II: effects of wind and body movement on local insulation. Int J Biometeorol 59(10): 1487-1498.

21. Suganthi T, Senthilkumar P, Dipika V (2017) Thermal Comfort Properties of a Bi-layer Knitted Fabric Structure for Volleyball Sportswear. FIBRES \& TEXTILES in Eastern Europe 25(1): 75-80.

22. Psikuta A, Allegrini J, Koelblen B, Bogdan A, Annaheim S, et al. (2017) Thermal manikins controlled by human thermoregulation models for energy efficiency and thermal comfort research - A review. Renewable and Sustainable Energy Reviews 78: 1315-1330.

23. Tama D, Catarino A, Abreu MJ (2019) Evaluating the Effect of WaterRepellent Finishing on Thermal Insulation Properties of Rowing Shirts Using a Thermal Manikin, Tekstil ve Konfeksiyon 29(4): 279-288.

24. Xu X, Rioux TP, Pomerantz N, Tew S (2019) Effects of fabric on thermal and evaporative resistances of chemical protective ensembles, Measurement and quantification. Measurement 136: 248-255.

25. Lei Z (2019) Review of application of thermal manikin in evaluation on thermal and moisture comfort of clothingJournal of Engineered Fibers and Fabrics 14: 1-10.

26. Tama D, Isler M, Abreu MJ ( 2020) Evaluating the thermal comfort properties of Rize's traditional hemp fabric (Feretiko) using a thermal manikin. Materials Today: Proceedings 31: 197-200.

27. Guan M, Li J (2020) Garment size effect of thermal protective clothing on global and local evaporative cooling of walking manikin in a hot environment. International Journal of Biometeorology 64: 485-499.

28. Rogale D, Majstorovi' G, Rogale SF (2020) Comparative Analysis of the Thermal Insulation of Multi-Layer Thermal Inserts in a Protective Jacket, Materials 13(12): 2672. 